\title{
The Influence of Digital Economy on Employment in China's Labor Market: Mechanism, Characteristics and Strategies
}

\section{Chenzi WU}

Northwest University, Xi'an, China; chenziwu90@hotmail.com

\begin{abstract}
Chinese economy is transforming from an industrial economy to a digital economy and accelerating the changes of China's labor market. Firstly, this paper explores the influence mechanism of digital economy on employment from the perspective of digital economy and proposes that digital economy has an influence on employment through the triple effects of substitution, creation, and matching. Secondly, it analyzes the characteristics of new forms of employment in China's labor market. The digital economy has become an important driving force for China's employment growth, and it is also facing the challenges from the changes in total volume, structure, and required vocational skills of employment. Finally, it puts forward the strategies on how to optimize the employment of Chinese labor force in the era of digital economy, including digital skills training, social support policies, and support for independent entrepreneurship to respond to the challenges of employment and Facilitate the coordinated development of digital economy and employment effectively.
\end{abstract}

Keywords: digital economy; China's labor market; new forms of employment

JEL Classification: O15; J21; J40

\section{Introduction}

With the rapid development of Chinese economy, the digital economy has become a critical driving force for Chinese economic and social development. According to a report released by the China Academy of Information and Communications Technology (CAICT) (2020), China's digital economy was valued at 35.8 trillion yuan ( $\$ 5.5$ trillion) in 2019 , which was second only to the United States worldwide, accounting for 36.2 percent of China's GDP and contributing 67.7 percent to its GDP growth. China's digital transformation now is expanding from the demand side to the supply side, from marketing to the upstream of the industrial chain, such as logistics, manufacturing and research and development. According to Okun's Law, an increase in GDP of $2 \%$ reduces the unemployment rate by $1 \%$. The development of China's digital economy will greatly promote the development of employment. The development of digital economy has made significant contributions to the social development, such as the lower production costs and higher-quality goods and services, etc. However, it is also facing the challenges brought about by the changes in total volume and structure of employment, such as imbalance in the supply and demand of digital skilled talents and structural contradictions in employment. Therefore, the study of the influence of digital economy on employment in China's labor market under the new 
situations has a theoretical and practical significance for promoting the coordinated development of digital economy and employment effectively.

Since the beginning of the new century, the researches on digital economy and employment have been continuously increased and enriched. As of the end of December 2020, a total of 23,466 related articles were found by searching the database of Web of Science and China National Knowledge Infrastructure (CNKI) with the subject of "digital economy" : 9,449 from the Web of Science and 14,017 from the CNKI. After 2015, the research on digital economy showed a blowout growth, which has a great research value. In addition, an advanced search was conducted on the subject of digital economy and employment, and 420 and 78 valid articles were obtained in the Web of Science database and the CNKI database respectively. The related research has gradually increased during the past four years.

According to the existing literature, the research on digital economy, digital transformation, artificial intelligence, labor market and employment has attracted increasing attention from researchers. And the research on employment is mainly reflected in such key words as technical unemployment, employment structure, organizational forms, labor ability, digital talent, top-level design and promotion of employment. It can be found that the requirements for vocational skills and skill transition have become a current research hot spot in the era of digital economy, however the research on the influence of digital economy on employment in labor market is insufficient. Therefore, this paper focuses on the employment in China's labor market from the following aspects: First, from the perspective of digital economy, the influence mechanism of the development of digital technology on employment in China is discussed. Second, it analyzes the characteristics of new employment forms in China's labor market under the background of digital economy, and finally puts forward the strategies on how to optimize the employment of Chinese labor force in the era of digital economy.

\section{The Influence Mechanism of Digital Economy on Employment in China}

The influence of the digital economy on employment in China can be shown in Figure 1. As a new economic form, the digital economy is manifested not only in the progress of Internet technology, but also in new production factors such as digital knowledge and information. Under these two manifestations, digital technologies and the real economy are deeply integrated to form a new economy. The new economy refers to fostering new drivers of growth and encouraging China's economic transformation, which includes three levels: new industries, new business forms and new business models. The development of the new economy creates a large number of new vocations and new jobs, changes the traditional ways of hiring and working, increases the number of jobs, and demands the higher requirements for worker's vocational skills, etc. Specifically, the digital economy affects future employment in the labor market through three mechanisms: substitution effect, creation effect and matching effect. 


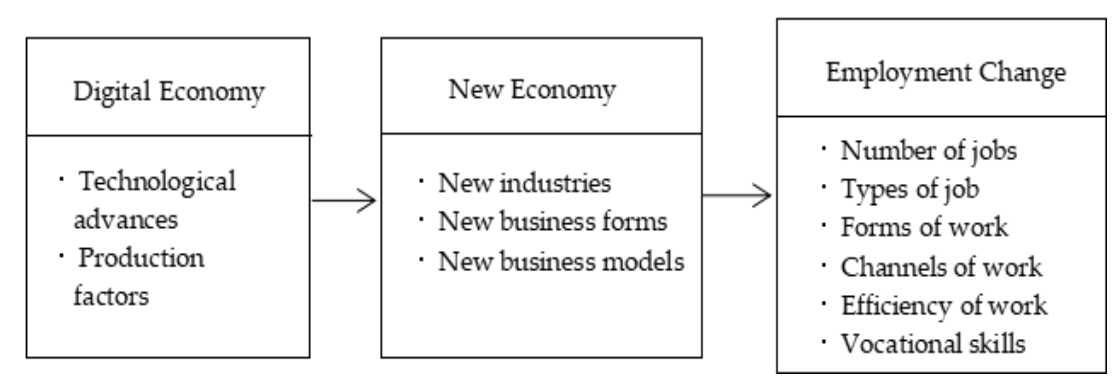

Figure 1. The influence of digital economy on employment in China

\subsection{Employment Substitution Effect}

The development of China's digital economy is mainly based on big data, cloud computing, artificial intelligence, the internet of things and 5G, and is reflected in the digitization of industries, such as the development of intelligent agriculture, intelligent manufacturing, digital services, digital logistics and other fields. China's supply-side structural reform strategy emphasizes eliminating superfluous industrial capacity, cutting business costs, and speeding up the development of emerging industries and enterprises, etc. This strategy has accelerated the effective integration of technology in major industries and forced traditional labor-intensive enterprises to transform. Therefore, the low-skilled workers who work in this type of work will be out of the labor market, it was replaced with the intelligent equipment and digital skilled talents.

Employment substitution mainly occurs in the front-line workers of traditional manufacturing, loading and unloading in logistics, traditional agriculture, and other lowskilled workers. For example, Cainiao Network Technology, the logistics affiliate of Alibaba Group implements the IoT strategy of logistics, i.e., the internet of things technology applied to logistics, realizes the digital connection of parcels, and replaces a large number of logistics warehouse keepers, operation center porters, and end sorting personnel (Guo, 2020). In Shentong Express, a Chinese logistics company, its intelligent robot sorting system to improve the sorting efficiency of goods can save more than $70 \%$ of the labor cost (Zhao, 2019). In "the black lamp" factory of Foxconn Industrial Internet Company, 18 working scenes were digitally upgraded, saving labor costs by $88 \%$ and increasing production efficiency by 2.5 times ( $\mathrm{Li}, 2020)$. Thus, digitization greatly reduces labor costs, creates more profits for enterprises, and at the same time squeezes out a large number of labor.

\subsection{Employment Creation Effect}

With the development of digital economy, the employment substitution effect of digital economy on the labor market will reduce the employment of low-skilled personnel to some extent in the short term. In the long term, as a new factor of production, digital information accelerates the emergence of new enterprises at a lower cost and creates the new opportunity for employment. As the labor market gradually adjusts to economic development trends and laborers adapt to the needs of emerging jobs, the employment creation effect formed by the digital economy may exceed the employment substitution effect. 
At present, China's digital economy is leading the emergence of new businesses such as information consumption, new retail and streaming media, including the latest 5G and artificial intelligence. Relevant data show that in 2018, there were 191 million jobs in the field of digital economy in China, accounting for $24.6 \%$ of the total number of jobs in that year, with a year-on-year growth of $11.5 \%$, significantly higher than the growth rate of the total employment scale in the same period of the country. The newly prosperous e-commerce sector has created 10 million jobs through online shops and related services, creating $1.3 \%$ of China's total employment. In April 2019, Chinese Ministry of Human Resources and Social Security released information on 13 new jobs, mainly focusing on new jobs derived from the digital economy and artificial intelligence technology. According to the Employment Report of Digital Culture Industry (2020) released by the Employment Research Institute of Renmin University of China in November 2020, the total number of full-time and part-time employees in the four digital cultural industries, including games, e-sports, live broadcasting and literature, reached about 30 million (Ding, 2020), and digital jobs became an important part of jobs in the cultural industry. The employment creation effect of the digital economy strongly offsets its employment substitution effect.

\subsection{Employment Matching Effect}

The most basic characteristic of the Internet is the openness, transparency and real-time of the information platform, which avoids the disadvantages of the mismatch and asymmetry of supply and demand information in the traditional labor market. With the help of big data information and Internet platform, digital economy will constantly share information, dynamically match the information of supply and demand, and create various forms of job opportunities in a more flexible way of employment (Ji, 2017).

In China, digital industrialization and industrial digital transformation in various regions are mutually promoting each other. The employment ecology built by digital technology and digital economy has improved the matching efficiency of workforce from the following three aspects: First, the digital infrastructure. As a country with the fastest development of Internet and supporting infrastructure, China has ensured the possibility of improving the efficiency of market-oriented allocation of labor resources from the perspective of development environment and alleviated the problem of information asymmetry in the traditional labor market to the greatest extent. Second, the applications of digital equipment. Under the general trend that 5G network will be fully applied, the penetration rate of mobile phones in China is very high. In 2020, the number of mobile phone users in China is 1.594 billion, with a penetration rate of 113.9 units per 100 people, and smart phones enhanced the mobility of workers' cross-province and cross-industry employment through the instant dissemination of information and various software applications (Cong \& $\mathrm{Yu}, 2020$ ). Third, the innovation of the government administrative mode. At present, the development of digital technology has promoted the efficiency and quality of social security systems such as "smart + medical" and "smart + education" and basic public services, so improving the matching efficiency of supply and demand of workforce and promoting the gradual deepening of the market. 


\section{The Characteristics of New Forms of Employment in China's Labor Market}

\subsection{The Employment Growth Driven by Digital Economic Growth}

It is still a controversial issue for economists to give conclusion whether the digital economy is positive to employment growth. The general views consider the combination of computerization and artificial intelligence will replace the workers confined to routine tasks involving explicit rule-based activities, even worse, some simple service jobs (Frey \& Osborne, 2017). However the economic statistics from China as described in Figure 2, both economic scale and corresponding employment maintain a remarkable increase even the general GDP and employment growth decelerated in recent years. According to statistics from the China Communications Industry Institute, in 2007, China's digital economy accounted for $14.7 \%$ of its GDP and created 44.11 million jobs. Over the past decade, the digital economy continues to maintain a rapid expansion of scale. In 2018, the scale of the digital economy reached 31.3 trillion yuan, with a nominal growth of $20.9 \%$ on a comparable basis, accounting for $34.8 \%$ of GDP. The number of jobs in the digital economy was 191 million, accounting for $24.6 \%$ of the total employment in the same year, with a year-on-year growth of $11.5 \%$ (CAICT, 2019), significantly higher than the growth of the total employment in the same period. Quite a number of Chinese researchers believe that the digitization in China's industrial upgrade process undoubtedly replace the low-skilled workforce continuously, however the disappeared jobs of low-end manufacturing will shift towards millions of new jobs in service sectors and total number maintains increasing (Zhang \& Chen 2019).
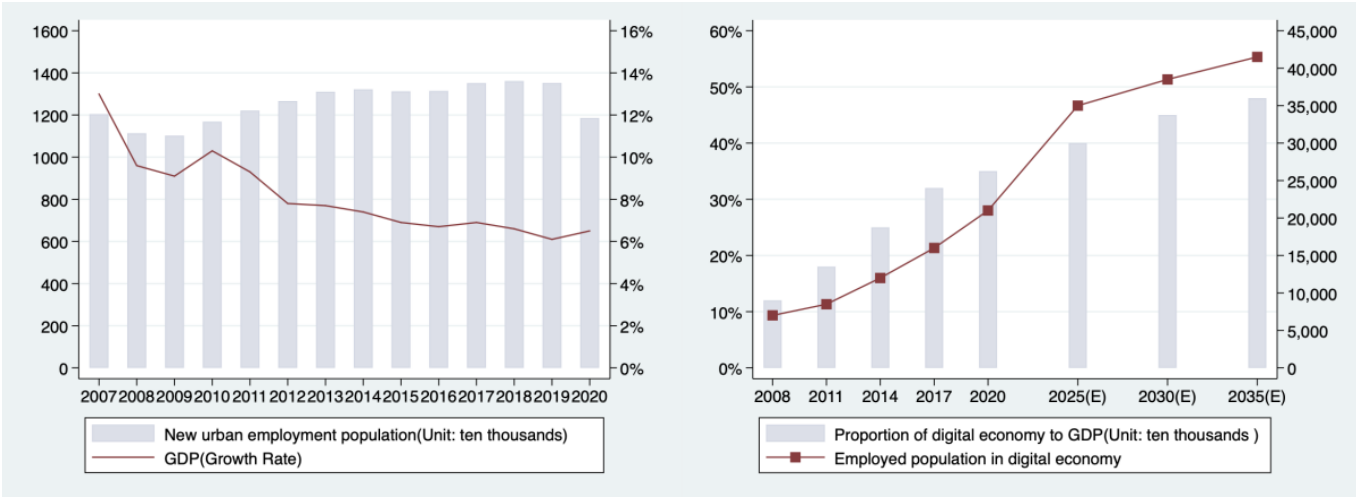

Figure 2. The relationship between economic growth and employment in China. Data Source: China's Statistical Report on National Economy and Social Development, China's White Paper on Digital Economy Development and Employment on 2019, China's White Paper on digital economy development on 2020 \& Study Report from Boston Consulting Group

\subsection{The "3-1-2" Employment Structure Characterized by Digital Economy}

Digital economy has a huge impact on the employment structure. From the perspective of employment structure of industries, the employment proportion of the tertiary industry will continue to rise, the primary industry will further improve the scale, intensive and intelligent level, and more agricultural labor force will be released by agricultural automation. Employment in the secondary industry (traditional manufacturing) will continue to decline. In 2018, there were 19.28 million jobs related to the digital transformation of the primary 
industry, accounting for 9.6 percent of the total number of jobs in the primary industry, an increase of about 2 percent. The number of digital transformation jobs in the secondary industry was 52.21 million, accounting for 23.7 percent of the total number of jobs in the secondary industry, an increase of about 1.4 percent. There are about 134.26 million jobs in the digital transformation of the tertiary industry, accounting for $37.2 \%$ of the total number of jobs in the tertiary industry, accounting for an increase of about $4 \%$ (CCIRI, 2019). It can be seen that the proportion of digital transformation jobs in the tertiary industry has increased the fastest, and the proportion of the secondary industry has increased the slowest. The employment absorption of the digital economy presents a "3-1-2" structural feature, because the digital transformation of the labor force in the tertiary industry is the least difficult. Digital transformation of the labor force in the secondary industry is the most difficult.

\subsection{The Flexible and Diversified Forms Employment}

Crowdsourcing and "Gig Economy" are new forms of digitally mediated employment that involves the performance of tasks online for a fee by distributed independent workers. They not only created many jobs in platform companies but also create numerous jobs for those part-time employees. On top of crowdsourcing, the rapid development of new business forms with digital economy, such as platform economy, sharing economy, and crowd innovation, has led to profound changes in employment. The typical characteristic of this new economy is that practitioners will never be required fixed working time and places. This kind of flexible and diversified employment forms caused by digital technology development leads to a prosperity in labor market. According to the statistics from Chinese authorities, the compound growth trend of "flexible employment" in China has increased from $2.7 \%$ to $9.1 \%$ during 2013 to 2017, showing an obvious and well growth trend (Zhang, 2017). Chinese Internet giants like Tencent and Alibaba both have dabbled in the crowdsourcing businesses and obtain considerable profits. However, negative effects like high probable unemployment and vulnerable social insurance are unignorable problems to be solved (Gol et al., 2019).

\subsection{The Higher-Level Education Proportion in Digital Practitioners}

The educational level of workforce correlates strongly with the degree of employment in digital sectors. In digital developed countries, the jobs require analytic skills and computing skills have a strong demand which implies the higher education is indispensable for digital economy (Lovaglio et al., 2018). From the perspective of the educational structure of the new employment groups, in China's urban labor market, the educational level of the new labor force has changed from junior high school graduates to higher education graduates. For example, from $13.8 \%$ and $17.1 \%$ of the first batch of college students entering the labor market (2002 and 2003) after the expansion of higher education enrollment increased to $67.8 \%$ in 2019. In 2016, 55.1\% of the full-time drivers on China's network platforms had high school education, and $20.7 \%$ had higher education. Among the part-time drivers, $43 \%$ have high school education and $44.8 \%$ have higher education, which is also much higher than the corresponding proportion of the national employed population (Ji, 2020). According to the 
annual report on the employment quality of graduates in 2019 released by Peking University (2019), the proportion of flexible employment of graduates with master's or doctoral degrees is increasing, among which the proportion of flexible employment of graduates with master's degree in 2019 reached $42.44 \%, 4.01 \%$ higher than that of 2018. The proportion of $\mathrm{PhD}$ graduates in flexible employment is $25.67 \%$, an increase of $3.11 \%$ compared with 2018 .

\subsection{The Severe Shortage of Digital Talents}

In the context of accelerating industrial automation and intelligent technological transformation in various regions, China's employment problem has increasingly caused a structural contradiction related to the required labor skills (Cai, 2017). At present, there is a larger supply gap of new digital skilled workers in China. The digital talents can be divided into three categories: general digital talents, professional digital talents and supplementary digital talents. In China, the supply and demand of general digital talents is relatively balanced. The supply of professional digital talents cannot meet market demand, for the training of digital skills is still insufficient. For supplementary digital talents, they mainly include high-skilled talents with rich practical experience such as digital transformation leaders and strategic leaders, which have a severe shortage in China (Chen \& Ma, 2018). Also, a survey showed nearly 40 million digital talents among all Linkedin's users in 31 cities worldwide, and found that the proportion of digital talents in the ICT sector in China is higher than that in Europe and the US, while the percentage of digital talent in traditional industries in Western countries is higher than that in China. In addition, most China's digital talents only have digital skills, while their counterparts in the West also have industry and business skills and experience. These findings show that compared with developed countries, China still lags behind in digitalizing traditional industries (Chen, 2021). China needs to nurture or find interdisciplinary talent with digital literacy and management skills in industries and other fields of the value chain to facilitate its digital transformation.

\section{The Strategies to Optimize Employment of Chinese Labor Force}

\subsection{Improving a New, Flexible and Personalized Employment Service System}

The employment service system is the basis for regulating the labor market to achieve full employment. At present, the construction of China's public employment service system is not perfect. For example, the scope, content and procedure of employment services are difficult to adapt to the new employment forms. Therefore, a new, flexible and personalized employment service system is urgently needed. First, building a diversified employment service system. It focuses on public employment services at the five levels of provinces, cities, districts, townships, and villages. It is composed of various types of employment service agencies, enterprises, universities, NGO, and NPO in the society to enrich the content of employment services and improve the service process. Second, the government and nonprofit organizations work together to effectively use Internet technology to build a digital platform for employment and entrepreneurship services, use big data resources to dig into the employment and entrepreneurship dynamic information in labor market, improve 
traditional employment service methods, and provide timely and personalized employment services for the labor market. Third, making full use of the flexible features of the Internet to develop online employment services in the human resource service industry and improve the professional level of employment services. Fourth, formulating a labor market employment and entrepreneurship service standard system that adapts to flexible employment, and form a unified service procedure, management method and business process to improve the quality of employment services.

\subsection{Improving the Basic Support Policies for New Forms of Employment}

The digital economy drives the vigorous promotion of new forms of employment, using digital technology to innovate employment and entrepreneurship support platform, social security, household registration system and other services. First, ensuring the policies to be implemented at all range. And the improvement of employment and entrepreneurship policies that adapt to new forms of employment, focus on the formulation of employment policies for special groups such as college students and the disabled, and solve the difficulties in the process of employment or reemployment of workers due to insufficient digital economic skills. Second, government should take measures to eliminate the digital divide existed in the traditional workforce in order to avoid the crowd-out effects. Establishment of the digital talent training mechanism is the responsibilities of companies, but relevant government departments should play a leading role, supporting the workforce by clear employment policies, vocational training subsidies and other insurance policies. Third, eliminating barriers to the population flow between the urban area and urban area. Due to the reduction of development between the urban and rural area in digital age, it is necessary to release the potential power of employment market in rural area. Only by eliminating the barriers to household registration can we better attract digital talents and promote the sustainable development of the digital economy.

\subsection{Strengthening Laborer's Digital Vocational Skills Training}

As talent is the most important resource, digital talent is the foundation underpinning the future of the digital economy. To better tap the digital talent dividend and make up for its talent shortage, China needs to drive supply-side reforms of its labor market and education with digital skills and education that is tailored to industry needs and scientific breakthroughs. Therefore, first, improving the government support system to facilitate school-enterprise cooperation, and strengthening the construction of digital related professional disciplines and the training of digital talents. Colleges and universities should optimize the construction of disciplines and specialty structures and introduce the construction of digital and information practice bases to increase the supply of digital skills talents needed to adapt to the digital economy. With an emphasis on the integration of digital technologies with other scientific and engineering fields, China should nurture more cuttingedge digital talent with disruptive digital skills to expedite its digital transformation. Second, increasing social vocational skills training. Government departments should play a leading role, support enterprises to build professional vocational skills training departments, and 
vigorously carry out enterprise digital skills upgrading and transfer professional training; outsource vocational skills training for the unemployed, disabled persons and other special employment groups to professional institutions to increase the supply of vocational skills training. Third, increasing subsidies for vocational training. On the one hand, subsidies can effectively stimulate the training initiative of vocational training providers; on the other hand, free training or corresponding subsidies can attract rural surplus labor, reemployed groups, and vocational skilled personnel to actively participate in vocational skills or transfer training.

\subsection{Increasing Support for Digital Innovation and Entrepreneurship}

The advancement of Internet technology has activated market innovation and entrepreneurship. Only by effectively marketing digital innovation projects can the quality of entrepreneurship projects be improved. Therefore, it is necessary to increase support for innovation and entrepreneurship in the ear of digital economy. First, actively introducing entrepreneurial support policies to encourage independent entrepreneurship. Relevant government departments should support digital entrepreneurship, the construction of digital entrepreneurship and incubation bases, expand financing channels for digital platform entrepreneurship, solve the source of mass entrepreneurship, and provide housing security policies for special groups of entrepreneurs to encourage active start a business. Second, increasing innovation and entrepreneurship training and improving the quality of innovation and entrepreneurship services. Colleges and universities should strengthen the popularization of innovation and entrepreneurship courses, guide college students' innovation and entrepreneurship projects, and cultivate their innovative thinking and entrepreneurial abilities. At the same time, the government should organize social organizations to provide professional entrepreneurial skills training for groups interested in starting a business, so as to increase the employment capacity of the labor market. Third, building a digital entrepreneurial service platform to provide continuous entrepreneurial support services. All provinces, districts, and cities should set up entrepreneurship counseling service centers to provide entrepreneurs with entrepreneurial services in a timely manner to help workers in the entrepreneurial stage solve problems.

\section{Conclusions}

The digital economy is a new economic form that has emerged with the development of human society. It has become a critical driving force for global economic and social development. In the process of the transformation from the industrial economy to the digital economy, the digital economy influences on the employment in China's labor market through the triple effect of substitution, creation, and matching, which has brought about many new characteristics of China's employment. Entering the era of digital economy, Chinese labor market is trending towards platform economy, sharing economy, crowdsourcing, crowd-creation and other new employment forms. The ways of employment are becoming more and more flexible and diversified. Employment opportunities have undergone tremendous changes, and digital skills have become laborer's basic employment 
skills. However, It is also facing some problems, such as imbalance in the supply and demand of digital skilled talents and structural contradictions in employment. Therefore, In the era of the digital economy, strengthening laborer's digital skills training, improving social support policies and employment service systems, increasing support for independent entrepreneurship are the strategies for optimizing employment of labor force in the labor market, which will effectively solve the employment problems to promote the coordinated development of digital economy and employment and China's digital transformation.

\section{References}

China Academy of Information and Communications Technology (CAICT). (2020). White Paper on China's Digital Economy Development on 2020. http://m.caict.ac.cn/yjcg/202007/P020200703318256637020.pdf

Guo, G. E. (2020). Analysis of the Development Status and Trends of China's E-commerce Express Industry. Business Economics Research. 16, 118-121.

Zhao, K. F. (2019). Operation Performance Evaluation of Shentong Express. Logistics Engineering and Management, 5, 60-63. https://10.3969 /j.issn.16744993.2019.05.023

Li, H. L. (2020). Industrial Fulian turned around. 21st Century Business Review, (4), 44-47.

Ding, R. (2020, November 6). The Employment Report of Digital Culture Industry (2020). School of Labor and Human Resources, Renmin University of China. https://news.ruc.edu.cn/archives/296180

Ji, W. W. (2017). Digital Economy and the Future of Work. Journal of China Institute of Industrial Relations. 6, 37-47.

Cong, Y., \& Yu, B. Y. (2020). The Influence of Digital Economy on the Efficiency of Chinese Labor Force Resource Allocation. The Theory and Practice of Finance and Economics, 42(2), 108-114. https://10.16339/j.cnki.hdxbcjb.20200403.001

Frey, C. B., \& Osborne, M. A. (2017). The future of employment: How susceptible are jobs to computerisation? Technological forecasting and social change, 114, 254-280. https://doi.org/10.1016/j.techfore.2016.08.019

China Academy of Information and Communications Technology (CAICT). (2019). White Paper on China's Digital Economy Development and Employment (2019).

https://wenku.baidu.com/view/a1a7c0d469ec0975f46527d3240c844768eaa076.html

Zhang, M. L., \& Chen, M. S. (2019). China's digital economy: Opportunities and risks. International Monetary Fund Working Papers. https://www.sipotra.it/wp-content/uploads/2019/03/Chinas-Digital-EconomyOpportunities-and-Risks.pdf

China Commercial Industry Research Institute (CCIRI). (2019, April 25). In 2018, there were 191 million jobs in my country's digital economy, accounting for $24.6 \%$ of total employment. https://www.askci.com/news/chanye/20190425/1737271145399.shtml

Zhang, C. W. (2017). Green Book of Population and Labor: Reports on China's Population and Labor (No. 18). Beijing: Social Science Literature Press.

Gol, E. S., Stein, M. K., \& Avital, M. (2019). Crowdwork Platform Governance toward Organizational Value Creation. The Journal of Strategic Information Systems, 28(2), 175-195. https://doi.org/10.1016/j.jsis.2019.01.001

Lovaglio, P. G., Cesarini, M., Mercorio, F., \& Mezzanzanica, M. (2018). Skills in demand for ICT and statistical occupations: Evidence from web-based job vacancies. Statistical Analysis and Data Mining: The ASA Data Science Journal, 11(2), 78-91. https://doi.org/10.1002/sam.11372

Ji, W. W. (2020). The main characteristics and development trends of China's new employment patterns. New Economic Guide, 3, 17-28.

Peking University. (2019). Annual Report on the Employment Quality of Peking University Graduates. Peking University Admissions Office. http://cdn1.kybimg.com/ohr/2020/01/06/135743_5e12cc57a9c25.pdf

Cai, F. (2017). Analysis of the Effects of China's Economic Reform: A Perspective of Labor Force Reconfiguration Angle. Economic Research, 7, 4-17.

Chen, Y., \& Ma, Y. F. (2018). Digital talent: the core driving force of the digital transformation of the Chinese economy. Tsinghua Management Review, (Z1), 30-40.

Chen, Y. B. ( 2021, January 28). Future of China's digital economy. China Daily Global. https:/www.chinadaily.com.cn/a/202101/28/WS6011fe41a31024ad0baa5911.html 